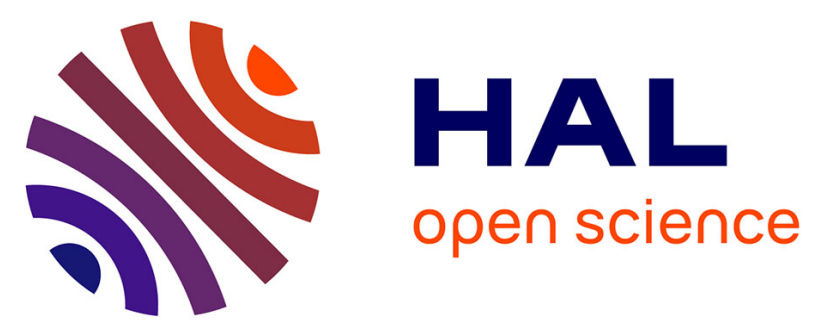

\title{
Preclinical characterization of a novel radiolabeled analog of practolol for the molecular imaging of myocardial $\beta$-adrenoceptor density
}

Eric Carbonnelle, Véronique Josserand, Laurent M Riou, Olivier Ormezzano, Alexis Broisat, Pascale Perret, Gilles Barone-Rochette, Daniel Fagret, Catherine Ghezzi

\section{To cite this version:}

Eric Carbonnelle, Véronique Josserand, Laurent M Riou, Olivier Ormezzano, Alexis Broisat, et al.. Preclinical characterization of a novel radiolabeled analog of practolol for the molecular imaging of myocardial $\beta$-adrenoceptor density: Imaging of Myocardial $\beta$-Adrenoceptor Density. Journal of Nuclear Cardiology, 2014, 21, pp.984 - 992. 10.1007/s12350-014-9913-5 . inserm-01077787

\section{HAL Id: inserm-01077787 https://www.hal.inserm.fr/inserm-01077787}

Submitted on 27 Oct 2014

HAL is a multi-disciplinary open access archive for the deposit and dissemination of scientific research documents, whether they are published or not. The documents may come from teaching and research institutions in France or abroad, or from public or private research centers.
L'archive ouverte pluridisciplinaire HAL, est destinée au dépôt et à la diffusion de documents scientifiques de niveau recherche, publiés ou non, émanant des établissements d'enseignement et de recherche français ou étrangers, des laboratoires publics ou privés. 


\section{Preclinical Characterization of a Novel Radiolabelled Analog of Practolol for the Molecular Imaging of Myocardial $\beta$-Adrenoceptor Density}

Eric Carbonnelle ${ }^{1,2}$, Véronique Josserand ${ }^{1,2}$, Laurent M. Riou ${ }^{1,2}$, Olivier Ormezzano $^{1,2}$, Alexis Broisat ${ }^{1,2}$, Pascale Perret ${ }^{1,2}$, Gilles Barone-Rochette ${ }^{1,2}$, Daniel Fagret ${ }^{1,2}$, Catherine Ghezzi ${ }^{1,2}$

${ }^{1}$ INSERM, UMR_S 1039, Radiopharmaceutiques Biocliniques, Grenoble, France $;{ }^{2}$ UJF-Grenoble 1, Grenoble, France

Correspondence \& reprints: Laurent M. Riou

Faculté de Médecine, Bâtiment Jean Roget

38700 La Tronche

Phone. 33(0)476 637509 Fax. 33(0)476 637142

Email. Laurent.Riou@ujf-grenoble.fr

Word count: 4,933

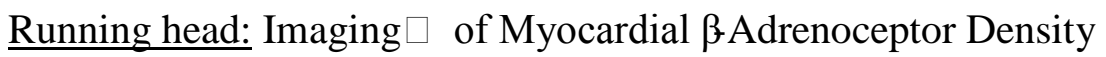




\section{ABSTRACT}

Background - The great clinical potential of myocardial $\beta$-AR imaging has been shown by recent studies evaluating the $\beta$-AR specific, non selective agent $\left[{ }^{11} \mathrm{C}\right]-$ CGP12177 in the setting of idiopathic dilated cardiomyopathy and myocardial infarction. However, the short half-life of ${ }^{11} \mathrm{C}$ hampers the potential of $\left[{ }^{11} \mathrm{C}\right]-$ CGP12177 for routine clinical use. AMI9 is an analog of the $\beta$-adrenoceptor ligand practolol that can readily be labeled using radioactive isotopes of iodine. The present study was aimed at characterizing the in vitro, ex vivo, and in vivo $\beta$ AR binding properties of $\left[{ }^{125} \mathrm{I}\right]$-AMI9.

Methods and Results - Newborn rat cardiomyocytes were used for saturation and kinetic binding assays as well as for displacement and competition experiments. Isolated perfused rat hearts were used to evaluate the pharmacological activity of AMI9. The in vivo kinetics of $\left[{ }^{125} \mathrm{I}\right]$-AMI9 were studied using biodistribution experiments in mice. [125 $\mathrm{I}$-AMI9 displayed high specific affinity for $\beta$-AR with no $\beta$-AR subtype selectivity $\left(K_{D}, 5.6 \pm 0.3 \mathrm{nM}\right.$; Bmax, 231 $\pm 7 \mathrm{fmol} / \mathrm{mg}$ of protein). AMI9 potently inhibited the inotropic effects of isoproterenol. The early in vivo cardiac and lung activities of $\left[{ }^{125} \mathrm{I}\right]$-AMI9 compared favorably with those of the clinically validated tracer CGP12177. Conclusions - Iodine-labeled AMI9 is a promising agent for the molecular imaging of myocardial $\beta$-AR density.

Key Words: basic science - radiopharmaceuticals - receptor imaging 


\section{ABBREVIATIONS}

AMI9, [(R,S)-(1-[4-(-4-iodobut-3-enecarboxamido)phenoxy]-3-

isopropylaminopropan-2-ol)]

AR, Adrenergic Receptors

DUR, Differential Uptake Ratio

HPLC, High Performance Liquid Chromatography

ICYP, Iodocyanopindolol

LV, Left Ventricle

NE, Norepinephrine

NRCM, Newborn Rat Cardiomyocytes

RBA, Relative binding Affinity

SNS, Sympathetic Nervous System 


\section{INTRODUCTION}

The cardiac SNS affects fundamental features of cardiac function such as systolic contraction, diastolic relaxation, myocardial blood flow, and heart rate through pre-synaptic release of the neurotransmitter NE by sympathetic neurons and postsynaptic binding of NE to $\alpha$ - and $\beta$ - AR on cardiac cells. Importantly, cardiac SNS dysfunction has been recognized to play major roles in the development of LV dysfunction, heart failure, and diabetic heart disease progression [1,2]. Pathophysiological modifications in $\beta$-AR density have been observed in a number of cardiac conditions [3] and more specifically in heart failure [1] and diabetic heart disease [2]. The non-selective, $\beta$-AR specific ligand $\left[{ }^{11} \mathrm{C}\right]-$ CGP12177 represents the most studied agent for the non invasive in vivo assessment of $\beta$-AR density in clinical settings such as non-ischemic cardiomyopathy and myocardial infarction $[4,5]$. $\left[{ }^{11} \mathrm{C}\right]-\mathrm{CGP} 12177$ predicted the improvement of cardiac function in patients with idiopathic dilated cardiomyopathy after long-term carvedilol treatment whereas dobutamine stress echocardiography did not [6], and Gaemperli et al. found that reduced myocardial $\beta$-AR density early after myocardial infarction was associated with the incidence of congestive heart failure on long-term follow-up [7]. In addition, recent studies have emphasized the clinical importance of assessing the presence of a potential mismatch in the cardiac SNS using agents targeted at the pre- and post-synaptic function $[8,9]$. Although such studies have provided proof-of-concept that $\beta$-AR imaging has great potential clinical interest by itself or in combination with a pre- 
synaptic agent, the development of an $\left[{ }^{11} \mathrm{C}\right]$-labelled PET imaging agent is limited by the extremely short half-life of the isotope (20.4 min).

$\beta$-blockers labeled with radioactive isotopes of iodine and therefore suitable for SPECT imaging have not proven successful so far due to either suboptimal affinity for $\beta$-AR or high nonspecific binding associated with high lipophilicity [10-13]. Studies performed with iodinated analogues of CGP-12177 also yielded negative results [14]. The aim of the present study was to perform the in vitro, ex vivo, and in vivo preclinical evaluation of AMI9, an analog of the $\beta$-AR ligand practolol, for the molecular nuclear imaging of $\beta$-AR density.

\section{MATERIALS \& METHODS}

The chemical structure of AMI9 is presented in Figure 1. Primary cultures of NRCM were prepared and used as previously described [15] to perform radioligand displacement experiments and binding assays while isolated and perfused rat hearts were used to determine AMI9 \& AMI9S pharmacological activities and swiss mice were used to evaluate $\left[{ }^{125} \mathrm{I}\right]-\mathrm{AMI} 9,\left[{ }^{3} \mathrm{H}\right]-\mathrm{CGP}-12177$, and $\left[{ }^{125} \mathrm{I}\right]-\mathrm{ICYP}$ in vivo biodistribution. Full details regarding these procedures as well as those used for AMI9 \& AMI9S chemical synthesis, radiolabeling, and determination of lipophilicity are provided in the supplementary data file. All experimental procedures were in accordance with Institutional Guidelines for Care and Use of Laboratory Animals. 


\section{RESULTS}

\section{Radioligand displacement experiments}

Competition curves between $\left[{ }^{3} \mathrm{H}\right]-\mathrm{CGP}-12177$ and AMI9 or AMI9S are shown in Figure 2. Both sets of data were best fitted monophasically, indicating a single class of affinity for $\beta$-AR. The competition curves between $\left[{ }^{3} \mathrm{H}\right]-\mathrm{CGP}-12177$ and alprenolol $(\beta)$, atenolol $(\beta 1)$, metoprolol $(\beta 1)$, pindolol $(\beta)$, propranolol $(\beta)$ and timolol $(\beta)$ presented similar profiles. Corresponding $\mathrm{K}_{\mathrm{I}}$, IC50 and RBA values are shown in Table 1. The rank order of increasing RBA was atenolol < metoprolol < AMI9S < AMI9 < propranolol < alprenolol < timolol < pindolol.

\section{Binding assays}

$\left[{ }^{125} \mathrm{I}\right]$-AMI9 and [125I]-AMI9S Scatchard curves for NRCM $\beta$-AR binding are shown in Figure 3. Bmax values with [125I]-AMI9 (KD: $5.6 \pm 0.3 \mathrm{nM})$ and [125I]-AMI9S (KD: $3.1 \pm 0.2 \mathrm{nM})$ were $231 \pm 7 \mathrm{fmol} / \mathrm{mg}$ prot, and $223 \pm 7$ fmol/mg prot, respectively. Plasmic membrane $\beta$-AR density was estimated at 85 $\pm 6 \mathrm{fmol} / \mathrm{mg}$ prot using $\left[{ }^{3} \mathrm{H}\right]-\mathrm{CGP}-12177(\mathrm{KD}: 1.0 \pm 0.1 \mathrm{nM})$ while total $\beta-\mathrm{AR}$ density as estimated using [125I]-ICYP reached $290 \pm 20 \mathrm{fmol} / \mathrm{mg}$ prot $\left(\mathrm{K}_{\mathrm{D}}: 0.4\right.$ $\pm 0.0 \mathrm{nM})$. In accordance with results from saturation experiments, the $\mathrm{K}_{\mathrm{D}}$ values of $\left[{ }^{125} \mathrm{I}\right]-\mathrm{AMI} 9$ and $\left[{ }^{125} \mathrm{I}\right]-\mathrm{AMI} 9 \mathrm{~S}$ as obtained from the analysis of the kinetics curves were $4.5 \mathrm{nM}$ and $2.6 \mathrm{nM}$, respectively (data not shown). 
The results from competition experiments aimed at assessing the specificity and selectivity of $\left[{ }^{125} \mathrm{I}\right]$-AMI9 and $\left[{ }^{125} \mathrm{I}\right]$-AMI9S binding are shown in Table 2 . Both $\left[{ }^{125} \mathrm{I}\right]-\mathrm{AMI}$ and $\left[{ }^{125} \mathrm{I}\right]$-AMI9S did not bind to muscarinic receptors as shown from the lack of effect of atropine. Conversely, $\alpha 1-, \alpha 2-, \beta 1-$ and $\beta 2$-selective blockers competed with [ $\left.{ }^{125} \mathrm{I}\right]-\mathrm{AMI}$ and $\left[{ }^{125} \mathrm{I}\right]$-AMI9S binding. The biphasic profiles observed in the presence of CGP-20712A, ICI 118551 and prazosin indicated subtype selectivity although yohimbine addition did not lead to a biphasic competition curve. At the highest concentration of competitor, AMI9 and AMI9S binding inhibition by CGP-20712A and ICI 118551 was similar to that observed with propranolol. Prazosin and phentolamine also had a comparable potential for AMI9 \& AMI9S binding inhibition.

\section{Pharmacological activity}

Propranolol, AMI9 and AMI9S inhibited the isoproterenol-induced increase in $\mathrm{dP} / \mathrm{dt}_{\max }$ of isolated perfused rat hearts in a dose-dependent manner (Table 3). A significant inhibition of isoproterenol-induced increase in contractility was observed with $1 \mathrm{nM}$ AMI9 and $10 \mathrm{nM}$ AMI9S or propranolol. The concentrations of propranolol, AMI9, and AMI9S required to reach half-maximal inhibition of the isoproterenol-induced increase in $\mathrm{dP} / \mathrm{dtmax}(\mathrm{CID} 50)$ were $5.9 \pm 0.8 \mathrm{nM}, 1.4 \pm$ $0.5 \mathrm{nM}$ and $3.7 \pm 2.1 \mathrm{nM}$, respectively 


\section{Lipophilicity}

The $\log (\mathrm{P})$ value of AMI9 was 0.613 . The retention coefficient $\left(\mathrm{k}^{\prime}\right)$ value of AMI9 (1.11) was lower than that of the lipophilic compound propranolol (1.43), comparable to that of the moderately lipophilic CGP-20712A (0.97) and higher than those of the hydrophilic compounds oxprenolol (0.78), CGP-12177 (0.13), and practolol (0.06).

\section{Biodistribution in mice}

The biodistributions of $\left.\left[{ }^{125} \mathrm{I}\right]-\mathrm{AMI},{ }^{3} \mathrm{H}\right]-\mathrm{CGP}-12177$ and $\left[{ }^{125} \mathrm{I}\right]-\mathrm{ICYP}$ are presented in Tables 4, 5 and 6, respectively.

[125I]-AMI9 - Blood tracer activity was maximal immediately following injection $(0.5 \mathrm{~min}, \mathrm{DUR}$ : $3.1 \pm 0.1)$ and then rapidly decreased to stabilize at $\sim 1.2$. In contrast, the cardiac radioactivity initially accumulated and peaked at 2 min p.i. (DUR: $5.3 \pm 0.5)$ prior to decreasing (120 min-DUR: $0.5 \pm 0.1)$. Pulmonary activity was 2 to 6 -fold higher than myocardial activity at all time points. The tracer was excreted predominantly though the kidneys with significant

involvement of the hepatic route as well. Low $\left[{ }^{125} \mathrm{I}\right]$-AMI9 activities were observed in the brain, muscle and fat (DUR range: brain, 0.1-0.3; muscle 0.3-1.2; fat, 0.1-0.5).

\section{[ ${ }^{3}$ H]-CGP-12177 - Blood tracer activity peaked immediately following} injection (0.5 min, DUR: $2.2 \pm 0.2)$ and decreased slowly thereafter to reach a minimal value of $0.6 \pm 0.1$ at 120 min p.i. The cardiac activity followed approximately the same kinetic pattern. Early pulmonary activity was comparable 
to that observed following injection of $\left[{ }^{125} \mathrm{I}\right]$-AMI9 but remained elevated at later time points with lung uptake typically being 5- to 10-fold higher than cardiac uptake. The renal and hepatic routes were equally involved in tracer excretion and liver activity was lower than that of $\left[{ }^{125} \mathrm{I}\right]-\mathrm{AMI}$. Finally, $\left[{ }^{3} \mathrm{H}\right]-\mathrm{CGP}-12177$ exhibited low brain, muscle and fat activities (DUR range: brain, 0.0 - 0.2; muscle, 0.4 - 0.9; fat, $0.1-0.6)$.

[125I]-ICYP - Blood tracer activity remained stable over time with DUR values within the $1.7 \pm 0.5$ and $2.7 \pm 0.1$ range. One-min cardiac radioactivity reached a maximum value similar to that of [125I]-AMI 9 and stabilized at a DUR of 2.1 from 15 min p.i.. Pulmonary uptake was 5 to 20 -fold higher than cardiac uptake at all time points and did not decrease significantly over time. No hepatic and renal accumulation of $\left[{ }^{125} \mathrm{I}\right]$-ICYP was observed. Finally, brain, muscle and fat also displayed low $\left[{ }^{125} \mathrm{I}\right]$-ICYP activities (DUR range: $0.07-0.12,0.5-0.8$ and $0.0-0.6$, respectively).

\section{DISCUSSION}

The affinity $\left(\mathrm{K}_{\mathrm{A}}\right)$ of radiolabeled $\beta$-AR ligands for $\beta$-ARs should approximate $10^{9} \mathrm{M}^{-1}$ [16], and the compounds should display $\beta$-blocker properties without inner sympathomimetic activity in order to form stable complexes with $\beta$-AR. As observed for most $\beta$-blockers, the asymmetry of the carbon carrying the secondary alcohol function of the AMI9 compound generates two optical enantiomers R and S. Since the S enantiomer of aryloxypropanolamines is generally better recognized by $\beta$-AR than the $\mathrm{R}$ enantiomer, an original synthesis 
pathway was developed for the obtention of AMI9S. The results from the present study indicated that $\left[{ }^{123} \mathrm{I}\right]$-AMI9 and $\left[{ }^{123} \mathrm{I}\right]$-AMI9S displayed high affinities for $\beta$ $\mathrm{AR}$ in vitro and ex vivo as well as in vivo kinetics suitable for non invasive cardiac imaging following intravenous injection.

In vitro binding experiments using the reference $\beta$-AR radioligands $\left[{ }^{3} \mathrm{H}\right]-\mathrm{CGP}$ 12177 and $\left[{ }^{125} \mathrm{I}\right]-\mathrm{ICYP}$ were performed to validate the NRCM model. The $\mathrm{K}_{\mathrm{D}}$ value for CGP-12177 $(1.0 \pm 0.1 \mathrm{nM})$ was in accordance with data obtained on rat intact cardiac myocytes (from $0.38 \pm 0.03 \mathrm{nM}$ to $3 \pm 1 \mathrm{nM}$ ) [17] and the Bmax (85 $\pm 6 \mathrm{fmol} / \mathrm{mg}$ prot) was close to that observed for plasma membrane $\beta$-AR by Yonemochi et al. (118 $\pm 18 \mathrm{fmol} / \mathrm{mg}$ prot) [18]. The KD value for ICYP $(0.4 \pm 0.0$ $\mathrm{nM}$ ) was found to be higher by approximately one order of magnitude than values generally observed in the rat heart (22-29 pM) [19] while Bmax $(290 \pm 20$ fmol/mg prot) was similar to that observed by Karliner et al. for the total amount of $\beta$-AR in a similar experimental model (260 $\pm 71 \mathrm{fmol} / \mathrm{mg}$ prot $)$ [20].

$\left[{ }^{3} \mathrm{H}\right]-\mathrm{CGP}-12177$ displacement assays on NRCM allowed the comparison of RBA values for AMI9 and AMI9S with those of well-known $\beta$-blockers. The rank order of increasing affinity for $\beta$-AR was in overall accordance with previously published values [21]. RBA values of AMI9 and AMI9S were intermediary between those of metoprolol and propranolol. As the latter has an affinity considered as minimal for a potential $\beta$-AR SPECT radioligand $\left(\mathrm{KD}_{\mathrm{D}}\right.$ from 0.76 to $6 \mathrm{nM})[16,22,23]$, the affinity of AMI9 and AMI9S is therefore suitable for use as $\beta$-AR SPECT ligands. Saturation and kinetic binding studies gave similar $\mathrm{KD}_{\mathrm{D}}$ 
values for AMI9 (5.6 $\pm 0.3 \mathrm{nM}$ vs $4.5 \mathrm{nM}$, respectively) and AMI9S $(3.1 \pm 0.2 \mathrm{vs}$ $2.6 \mathrm{nM}$, respectively). Affinity ratios between AMI9S and AMI9 (1.64, 1.79 and 1.75 depending on the binding study) were $\sim 2$ (theoretical ratio) and therefore confirmed the expected better activity of the $S$ enantiomer. Finally, the two-phase profiles of the competition curves between CGP-20712A or ICI 118551 and AMI9 or AMI9S provided evidence that AMI9 and AMI9S bind to both $\beta 1$ - and $\beta 2-\mathrm{AR}$. In addition, AMI9 and AMI9S poorly discriminated between $\beta$-AR subtypes as indicated by the results obtained with the one-site model used to fit the corresponding Scatchard curves. The Bmax values of AMI9 and AMI9S relative to NRCM $\beta$-AR were found to be identical, as expected for a racemic mixture in which the S-enantiomer only binds to receptors. Bmax values of both radioligands were therefore intermediary between those of $\left[{ }^{3} \mathrm{H}\right]-\mathrm{CGP}-12177$ and $\left[{ }^{125} \mathrm{I}\right]-\mathrm{ICYP}$, indicating that AMI9 bound not only to externalized $\beta$-AR but also to intracellular $\beta$-AR.

These results were in accordance with the moderate lipophilicity of AMI9, whose partition coefficient $(\log (\mathrm{P})=0.61)$ was intermediary between that of CGP-12177 and ICYP $(\log (\mathrm{P})=-0.52$ and 1.26 , respectively) [24]. HPLC analysis confirmed the moderate lipophilic nature of AMI9, close to that of oxprenolol and CGP20712A. AMI9 and AMI9S therefore appear well suited for those pathologies such as chronic heart failure in which global down-regulation of $\beta$-adrenoceptor expression occurs whereas their potential for diseases in which membrane receptors are being internalized will require further evaluation. 
Results from specificity studies indicated that AMI9 and AMI9S bound to both $\beta$ and $\alpha$-AR. Specificity ratios for CGP-20712A, ICI 118551 and prazosin from the present study were similar to those previously published. Indeed, $\beta 1$ : $\beta 2$ ratios for CGP-20712A (580:1 and 380:1) were close to those described by Birnbaumer et al. (845:1) [25]. Those for ICI 118551 (1:406 and 1:116) reflect the differences in the published ratios for this agent (1:54, 1:123, 1:225) [25-27], while the $\alpha 1: \alpha 2$ ratios for prazosin (3220:1 and 450:1) were around the generally observed relative values (1000:1 or 1590:1) [28, 29]. Human $\alpha$-AR myocardial expression represents approximately $10 \%$ and $25 \%$ of total AR expression in non-failing and failing human myocardium, respectively [30]. However, the potential poorer scintigraphic contrast resulting from AMI9 and AMI9S binding to $\alpha-\mathrm{AR}$ and due to a higher number of targets (vessels, atria, platelets) does not theoretically constitute constraints for in vivo quantification of $\beta$-AR in SPECT because Bmax determination will mostly depend upon the highly specific nature of the cold ligand used to study nonspecific binding. In addition, the IC50 of AMI9 for $\left[{ }^{3} \mathrm{H}\right]-$ prazosin and $\left[{ }^{3} \mathrm{H}\right]$-yohimbin to NRCM was $2.2 .10^{-5} \mathrm{M}$ and $1.2 .10^{-5} \mathrm{M}$, respectively (data not shown), whereas this value reached $1.9 .10^{-6} \mathrm{M}$ when $\left[{ }^{3} \mathrm{H}\right]-$ CGP12177 was used (Table 1), indicating that AMI9 had a much lower affinity for $\alpha-A R$ than for $\beta-A R$. AMI9 binding to $\alpha$-AR should therefore represent a minimal confounding actor while quantifying $\beta$-AR density from scintigraphic images.

$\beta$-AR imaging should avoid the use of $\beta$-AR agonists due to subsequent alterations in receptor conformation, binding dissociation, activation of 
intracellular reactions and consequently $\beta$-AR regulation mechanisms. Ligands should therefore display high $\beta$-blocking potency without inner sympathomimetic activity. AMI9 and AMI9S demonstrated such properties in isolated perfused rat hearts. Indeed, both compounds inhibited the $10 \mathrm{nM}$ isoproterenol-induced increase in contractility with a similar potency to that of propranolol without causing alterations in cardiac contractility when perfused alone at $1 \mu \mathrm{M}$ (data not shown).

$\left[{ }^{3} \mathrm{H}\right]-\mathrm{CGP}-12177$ and $\left[{ }^{125} \mathrm{I}\right]-\mathrm{ICYP}$ behaved as expected in in vivo mouse biodistribution studies. ICYP bound more than CGP-12177 to most tissues, likely due to the high lipophilicity of the former compound and therefore to its ability to bind to nonspecific targets as well as to all $\beta$-AR whereas the more hydrophilic CGP-12177 only bound to membrane receptors, resulting in lower heart uptake. $\left[{ }^{3} \mathrm{H}\right]-\mathrm{CGP}-12177$ and $\left[{ }^{125} \mathrm{I}\right]-\mathrm{ICYP}$ cardiac activities that were obtained in mice in the present study were consistent with previously published data in rats when considering the differences in heart-to-weight ratios between these 2 species [31]. The early cardiac washout of $\left[{ }^{125} \mathrm{I}\right]$-AMI9 and $\left[{ }^{125} \mathrm{I}\right]-\mathrm{ICYP}$ was higher than that of $\left[{ }^{3} \mathrm{H}\right]-\mathrm{CGP} 12177$ and the results did not seem to indicate that binding affinity represented a major determinant of the early in vivo cardiac kinetics of radiolabelled $\beta$-AR-specific ligands. Indeed, an order of magnitude was observed between the Kd of $\left[{ }^{125} \mathrm{I}\right]$-AMI9 and that of $\left[{ }^{125} \mathrm{I}\right]-\mathrm{ICYP}(5.6$ and $0.4 \mathrm{nM}$, respectively), yet both tracers exhibited a similar cardiac washout of $\sim 60 \%$ over the first 15 min following injection which was much greater than that of $\left[{ }^{3} \mathrm{H}\right]-$ CGP12177 ( 15\%) whereas the latter had a Kd roughly similar to that of $\left[{ }^{125} \mathrm{I}\right]-$ 
ICYP $(1 \mathrm{nM})$. Linear relationships have been described between the lipophilicity of compounds and their respective binding to plasma proteins [32]. A hypothesis that might account for greater early cardiac washout of [ $\left.{ }^{125} \mathrm{I}\right]$-AMI9 and $\left[{ }^{125} \mathrm{I}\right]-$ ICYP than $\left[{ }^{3} \mathrm{H}\right]-\mathrm{CGP} 12177$ could therefore be that the more lipophilic nature of $\left[{ }^{125} \mathrm{I}\right]$-AMI9 \& $\left[{ }^{125} \mathrm{I}\right]-\mathrm{ICYP}(\log (\mathrm{P})=0.61$ and 1.26 , respectively) when compared to that of $\left[{ }^{3} \mathrm{H}\right]-\mathrm{CGP} 12177(\log (\mathrm{P})=-0.52)$ resulted in increased cardiac washout through increased binding to plasma proteins.

[125I]-AMI9 biodistribution showed a significantly lower lung activity than that of the more lipophilic [ $\left.{ }^{125} \mathrm{I}\right]-\mathrm{ICYP}$ from 5 min p.i. Interestingly, [ $\left.{ }^{125} \mathrm{I}\right]-\mathrm{AMI} 9$ lung activity was similar to that of the hydrophilic [ $\left.{ }^{3} \mathrm{H}\right]-\mathrm{CGP}-12177$ in the first 5 min following injection and lower afterwards, reaching a CGP-12177/AMI9 DUR ratio of 4.7 at 90 min p.i. The moderate in vivo lung activity of AMI9 represents a favorable feature for high quality cardiac imaging. Considering the fact that $\left[{ }^{11} \mathrm{C}\right]-$ CGP12177 has been used clinically with no reports of lung activity impairing image acquisition and quantification, and since $\left[{ }^{125} \mathrm{I}\right]$-AMI9 lung uptake is lower than that of $\left[{ }^{3} \mathrm{H}\right]-\mathrm{CGP} 12177$, we believe that our results suggest that the pulmonary activity of $\left[{ }^{125} \mathrm{I}\right]$-AMI9 that was observed in the present study is suitable for further evaluation of the tracer in the clinical setting. Moreover, the fact that $\left[{ }^{125} \mathrm{I}\right]$-AMI9 cardiac activity was $\sim 1.5$ to 2 -fold higher than that of $\left[{ }^{3} \mathrm{H}\right]$-CGP12177 in the first $15 \mathrm{~min}$ following injection and $\left[{ }^{125} \mathrm{I}\right]$-AMI9 blood activity was $17-35 \%$ lower than that of $\left[{ }^{3} \mathrm{H}\right]$-CGP12177 between 1 and 15 min post-injection resulting in superior early heart-to-blood ratios for $\left[{ }^{125} \mathrm{I}\right]-\mathrm{AMI} 9$ whereas $\left[{ }^{3} \mathrm{H}\right]$-CGP12177 ratios were slightly superior afterwards. of the 
tracersThese results suggests that the potential for in vivo $\beta$-AR density imaging with AMI9 should be further evaluated with special emphasis on early postinjection time points.

\section{Conclusion}

The iodinated $\beta$-blocker analog of practolol AMI9 as well as its S enantiomer AMI9S exhibited high affinity for $\beta$-AR in vitro and ex vivo together with moderate lipophilicity. AMI9 is a promising iodinated ligand for the in vivo assessment of myocardial $\beta$-adrenoceptor density which requires further clinical evaluation.

\section{New Knowledge Gained}

Pathophysiological modifications in $\beta$-AR density have been observed in heart failure and diabetic heart disease. Although studies using $\left[{ }^{11} \mathrm{C}\right]-\mathrm{CGP} 12177$ have provided proof-of-concept that $\beta$-AR imaging has great potential clinical interest, the development of an $\left[{ }^{11} \mathrm{C}\right]$-labelled PET imaging agent is limited by the extremely short half-life of the isotope. The present study showed that the iodinated $\beta$-blocker analog of practolol AMI9 as well as its S enantiomer AMI9S exhibited high affinity for $\beta$-AR in vitro and ex vivo together with moderate lipophilicity and that both compounds are therefore promising iodinated ligands for the in vivo assessment of myocardial $\beta$-adrenoceptor density. 


\section{ACKNOWLEDGEMENTS}

This study was funded by grants from Commissariat à l'Energie Atomique,

Institut National de la Santé et de la Recherche Biomédicale (INSERM) and

CISBIO International / Groupe IBA (France).

\section{CONFLICT OF INTEREST STATEMENT}

The authors declare that they have no conflict of interest. 


\section{REFERENCES}

1. Triposkiadis F, Karayannis G, Giamouzis G, Skoularigis J, Louridas G, Butler

J. The sympathetic nervous system in heart failure - physiology, pathophysiology, and clinical implications. J Am Coll Cardiol. 2009;54:174762.

2. Thackeray JT, Beanlands RS, Dasilva JN. Altered sympathetic nervous system signaling in the diabetic heart: emerging targets for molecular imaging. Am J Nucl Med Mol Imaging. 2012;2:314-34.

3. Wachter SB, Gilbert EM. Beta-adrenergic receptors, from their discovery and characterization through their manipulation to beneficial clinical application. Cardiology. 2012;122:104-12.

4. Tsukamoto T, Morita K, Naya M, Inubushi M, Katoh C, Nishijima K, et al. Decreased myocardial beta-adrenergic receptor density in relation to increased sympathetic tone in patients with nonischemic cardiomyopathy. J Nucl Med. 2007;48:1777-82.

5. Ohte N, Narita H, Iida A, Fukuta H, Iizuka N, Hayano J, et al. Cardiac $\beta$ adrenergic receptor density and myocardial systolic function in the remote noninfarcted region after prior myocardial infarction with left ventricular remodelling. Eur J Nucl Med Mol Imaging. 2012;39:1246-53.

6. Naya M, Tsukamoto T, Morita K, Katoh C, Nishijima K, Komatsu H, et al. Myocardial beta-adrenergic receptor density assessed by 11C-CGP12177 PET predicts improvement of cardiac function after carvedilol treatment in patients with idiopathic dilated cardiomyopathy. J Nucl Med. 2009;50:220-5. 
7. Gaemperli O, Liga R, Spyrou N, Rosen SD, Foale R, Kooner JS, et al. Myocardial beta-adrenoceptor down-regulation early after infarction is associated with long-term incidence of congestive heart failure. Eur Heart J. 2010;31:1722-9.

8. Caldwell JH ${ }^{1}$, Link JM, Levy WC, Poole JE, Stratton JR. Evidence for pre- to postsynaptic mismatch of the cardiac sympathetic nervous system in ischemic congestive heart failure. J Nucl Med. 2008;49:234-41.

9. Schäfers $\mathrm{M}^{1}$, Dutka D, Rhodes CG, Lammertsma AA, Hermansen F, Schober O, Camici PG. Myocardial presynaptic and postsynaptic autonomic dysfunction in hypertrophic cardiomyopathy. Circ Res. 1998;82:57-62.

10. Eckelman WC, Gibson RE, Vieras F, Rzeszotarski WJ, Francis B, Reba RC. In vivo receptor binding of iodinated beta-adrenoceptor blockers. $\mathrm{J} \mathrm{Nucl} \mathrm{Med}$. 1980;21:436-442.

11. Rademaker B, Kramer K, Stroes JW, Vlug J, Krielaart M, Zaagsma J. High affinity non-beta-adrenoceptor binding of beta-adrenergic ligands. Eur $J$ Pharmacol. 1985;111:31-36.

12. Hughes B, Maeshall DR, Sobel BE, Bergmann SR. Characterization of betaadrenoreceptors in vivo with iodine-131 pindolol and gamma scintigraphy. $J$ Nucl Med. 1986;27:660-667.

13. Hanson RN, Holman BL, Davis MA. Synthesis and biologic distribution of radioiodinated beta-adrenergic antagonists. J Med Chem. 1978;21:830-833.

14. Dubois EA, Somsen GA, van den Bos JC, Janssen AG, Batink HD, Boer GJ, et al. Development of radioligands for the imaging of cardiac $\beta$-adrenoceptors 
using SPECT. Part II: Pharmacological characterization in vitro and in vivo of new 123I-labeled $\beta$-adrenoceptor antagonists. Nucl Med Biol. 1997;24:9-13.

15. Riou L, Ghezzi C, Mouton O, Mathieu JP, Pasqualini R, Comet M, et al. Cellular uptake mechanisms of 99mTcN-NOET in cardiomyocytes from newborn rats: calcium channel interaction. Circulation. 1998;98:2591-7.

16. Eckelman WC, Reba RC, Gibson RE, Rzeszotarski WJ, Vieras F, Mazaitis JK, et al. Receptor-binding radiotracers: a class of potential radiopharmaceuticals. J Nucl Med. 1979;20:350-357.

17. Kashiwagi A, Nishio Y, Saeki Y, Kida Y, Kodama M, Shigeta Y. Plasma membrane-specific deficiency in cardiac $\beta$-adrenergic receptor in streptozocindiabetic rats. Am J Physiol (Endocrinol. Metab). 1989;257:E127-E132

18. Yonemochi H, Saikawa T, Takakura T, Ito S, Takaki R. Effects of calcium antagonists on $\beta$-receptors of cultured cardiac myocytes isolated from neonatal rat ventricle. Circulation. 1990;81:1401-1408.

19. Kuznetsov V, Pak E, Robinson RB, Steinberg SF. $\beta 2$-adrenergic receptor actions in neonatal and adult rat ventricular myocytes. Circ Res. 1995;76:4052.

20. Karliner JS, Simpson PC, Taylor JE, Honbo N, Woloszyn W. Adrenergic receptor characteristics of cardiac myocytes cultured in serum-free medium: comparison with serum-supplemented medium. Biochem Biophys Res Commun. 1985;128:376-382.

21. Golf S, Hansson V. Relative potencies of various $\beta$-adrenoceptor antagonists (BAA) at the level of the human myocardial $\beta$-adrenoceptor-adenylate cyclase 
(AC) complex. Is intrinsic sympathomimetic activity (ISA) due to AC activation? Scand J Clin Lab Invest. 1986;46:121-130.

22. Kaumann AJ, Lemoine H. Direct labeling of myocardial $\beta 1$-adrenoceptors. Comparison of binding affinity of 3H-(-)-bisoprolol with its blocking potency. Naunyn-Schmiedeberg's Arch Pharmacol. 1985;331:27-39.

23. Ijzerman AP, Dorlas R, Aué GHJ, Bultsma T, Timmerman H. Factors controlling $\beta 1$-adrenoceptor affinity and selectivity. Biochem Pharmacol. 1985;34:2883-2890.

24. Staehelin M, Simons P, Jaeggi K, Wigger N. CGP-12177. A hydrophilic $\beta$ adrenergic receptor radioligand reveals high affinity binding of agonists to intact cells. J Biol Chem. 1983;258:3496-3502.

25. Birnbaumer L, Levy FO, Zhu X, Kaumann AJ. Studies on the intrinsic activity (efficacy) of human adrenergic receptors. Texas Heart Institute J. 1994;21:1621.

26. O'Donnell SR, Wanstall JC. Evidence that ICI 118, 551 is a potent, highly beta2-selective adrenoceptor antagonist and can be used to characterize betaadrenoceptor populations in tissues. Life Sciences. 1980;27:671-677.

27. Bilski AJ, Halliday SE, Fitzgerald JD, Wale JL. The pharmacology of a $\beta 2-$ selective adrenoceptor antagonist (ICI-118,551). J Cardiovasc Pharmacol. 1983;5:430-437.

28. Hoffman BB, Lefkowitz RJ. Catecholamines, sympathomimetic drugs, and adrenergic receptor antagonists. In: Hardman JG, Gilman AG, Limbird LE, 
eds. Goodman \& Gilman's The pharmacological basis of therapeutics. 9th ed. New York: McGraw-Hill, 1996, pp 199-248.

29. Michel AD, Whiting RL. The rat, isolated, transversely bisected vas deferens; a preparation for determining the potency of antagonists at both $\alpha 1$ - and $\alpha 2$ adrenoceptors. Br J Pharmacol. 1981;74:256P-257P.

30. Jensen BC, O'Connell TD, Simpson PC. Alpha-1-Adrenergic Receptors: Targets for Agonist Drugs to Treat Heart Failure. J Mol Cell Cardiol. 2011; 51: $518-528$.

31. van Waarde A, Meeder JG, Blanksma PK, Bouwer J, Visser GM, Elsinga PH, et al. Suitability of CGP-12177 and CGP-26505 for quantitative imaging of beta-adrenoceptors. Int J Rad Appl Instrum B. 1992;19:711-718.

32. Milošević NP1, Stojanović SZ, Penov-Gaši K, Perišić-Janjić N, Kaliszan R. Reversed- and normal-phase liquid chromatography in quantitative structure retention-property relationships of newly synthesized seco-androstene derivatives. J Pharm Biomed Anal. 2014;88:636-642. 


\section{FIGURE CAPTIONS}

\section{Figure 1}

Chemical structure of AMI 9.

\section{Figure 2}

Competition curves for binding to membrane $\beta$-adrenoceptors from newborn rat cardiac myocytes. a, AMI9 vs [ $\left.{ }^{3} \mathrm{H}\right]-\mathrm{CGP}-12177$; b, AMI9S vs $\left[{ }^{3} \mathrm{H}\right]-\mathrm{CGP}-12177$.

\section{Figure 3}

Scatchard curves indicating saturation of newborn rat cardiac myocyte $\beta$ -

adrenoceptors by $\left[{ }^{125} \mathrm{I}\right]$-AMI9 (a) and $\left[{ }^{125} \mathrm{I}\right]$-AMI9S (b). Bound = specifically bound radioligand (fmol/mg protein); $\mathrm{F}=$ free radioligand $(\mathrm{M})$. Nonspecific binding was assessed with $25 \mu \mathrm{M}( \pm)$-propranolol. 


\begin{tabular}{lccc}
\hline Compound & $\mathrm{K}_{\mathrm{I}}(\mathrm{M})$ & $\mathrm{IC} 50(\mathrm{M})$ & $\mathrm{RBA}$ \\
\hline Atenolol & $(1.1 \pm 0.2) \times 10^{-6}$ & $6.9 \times 10^{-6}$ & 35.6 \\
Metoprolol & $(3.9 \pm 0.5) \times 10^{-7}$ & $2.4 \times 10^{-6}$ & 12.6 \\
AMI9 & $(3.0 \pm 0.5) \times 10^{-7}$ & $1.9 \times 10^{-6}$ & 9.7 \\
AMI9S & $(1.8 \pm 0.3) \times 10^{-7}$ & $1.1 \times 10^{-6}$ & 5.9 \\
Propranolol & $(3.1 \pm 0.8) \times 10^{-8}$ & $1.9 \times 10^{-7}$ & 1.0 \\
Alprenolol & $(1.9 \pm 0.2) \times 10^{-8}$ & $1.2 \times 10^{-7}$ & 0.6 \\
Timolol & $(1.7 \pm 0.3) \times 10^{-8}$ & $1.1 \times 10^{-7}$ & 0.6 \\
Pindolol & $(7.9 \pm 1.0) \times 10^{-9}$ & $4.9 \times 10^{-8}$ & 0.3 \\
\hline
\end{tabular}

TABLE 1. $K_{I}, I C 50$ and relative binding affinity [RBA, $\left.\left(K_{\text {Icompound }} / K_{\text {Ipropranolol }}\right)\right]$ values of AMI9, AMI9S, and a series of reference $\beta$-blockers as obtained from $\left[{ }^{3} \mathrm{H}\right]-\mathrm{CGP}-12177$ displacement experiments on newborn rat cardiac myocytes. 


\begin{tabular}{|c|c|c|c|c|}
\hline & \multicolumn{2}{|c|}{$\left[{ }^{125} \mathrm{I}\right]-\mathrm{AMI} 9$} & \multicolumn{2}{|c|}{$\left[{ }^{125} \mathrm{I}\right]-\mathrm{AMI} 9 \mathrm{~S}$} \\
\hline & $\mathrm{K}_{\mathrm{I} 1}(\mathrm{M})$ & $\mathrm{K}_{\mathrm{I} 2}(\mathrm{M})$ & $\mathrm{K}_{\mathrm{I} 1}(\mathrm{M})$ & $\mathrm{K}_{\mathrm{I} 2}(\mathrm{M})$ \\
\hline CGP-20712A $\left(\beta_{1}\right)$ & $(3.8 \pm 2.8) \times 10^{-10}$ & $(2.2 \pm 1.1) \times 10^{-7}$ & $(8.1 \pm 7.0) \times 10^{-10}$ & $(3.1 \pm 0.8) \times 10^{-7}$ \\
\hline ICI $118551\left(\beta_{2}\right)$ & $(1.1 \pm 0.2) \times 10^{-6}$ & $(2.7 \pm 1.0) \times 10^{-9}$ & $(1.7 \pm 0.8) \times 10^{-7}$ & $(1.5 \pm 1.0) \times 10^{-9}$ \\
\hline $\operatorname{Prazosin}\left(\alpha_{1}\right)$ & $(1.1 \pm 1.0) \times 10^{-9}$ & $(3.7 \pm 1.7) \times 10^{-6}$ & $(8.3 \pm 3.4) \times 10^{-9}$ & $(3.8 \pm 1.3) \times 10^{-6}$ \\
\hline Yohimbine $\left(\alpha_{2}\right)$ & $\sim 10^{-3}$ & $(4.7 \pm 0.9) \times 10^{-9}$ & $\sim 10^{-3}$ & $(5.5 \pm 0.7) \times 10^{-9}$ \\
\hline Atropine (musc.) & $\mathrm{NC}$ & $\mathrm{NC}$ & $\mathrm{NC}$ & $\mathrm{NC}$ \\
\hline
\end{tabular}

$\overline{\text { TABLE 2. } \mathrm{K}_{\mathrm{I}} \text { values of selective inhibitors from displacement experiments of }\left[{ }^{125} \mathrm{I}\right] \text {-AMI9 and }\left[{ }^{125} \mathrm{I}\right] \text {-AMI9S }}$ binding on newborn rat cardiac myocytes. $\mathrm{K}_{\mathrm{I} 1}$ and $\mathrm{K}_{\mathrm{I} 2}$ refer to $\mathrm{K}_{\mathrm{I}}$ values for either the $\beta 1 / \alpha 1$ or the $\beta 2 / \alpha 2$ receptor subtypes. Musc., muscarinic; NC, no competition. 


\begin{tabular}{cccccccc}
\hline Compound & Dose (mol/L) & $\mathbf{n}$ & $\begin{array}{c}\text { dP/dt max } \\
\text { Baseline }\end{array}$ & $\begin{array}{c}\text { dP/dt max } \\
\text { Isoproterenol }\end{array}$ & $\begin{array}{c}\text { dP/dt max } \\
\text { co-perfusion }\end{array}$ & \% inhibition & P value \\
\hline $\begin{array}{c}\text { None } \\
\text { (Control) }\end{array}$ & & 6 & $715 \pm 325$ & $2535 \pm 1233$ & $2398 \pm 1088$ & $5.5 \pm 11.6$ \\
\hline Propranolol & $10^{-10}$ & 6 & $797 \pm 195$ & $2949 \pm 341$ & $2857 \pm 425$ & $4.7 \pm 14.4$ & 0.53 \\
& $10^{-9}$ & 6 & $1017 \pm 245$ & $2529 \pm 293$ & $2223 \pm 176$ & $20.9 \pm 7.5$ & 0.40 \\
& $10^{-8}$ & 6 & $837 \pm 176$ & $2170 \pm 325$ & $1271 \pm 200$ & $67.5 \pm 14.5$ & 0.007 \\
& $10^{-7}$ & 6 & $1004 \pm 144$ & $2586 \pm 266$ & $926 \pm 256$ & $105.9 \pm 11.5$ & 0.0001 \\
& $10^{-6}$ & 9 & $941 \pm 363$ & $2830 \pm 910$ & $767 \pm 218$ & $111.5 \pm 14.6$ & 0.0001 \\
& $10^{-5}$ & 4 & $905 \pm 361$ & $1854 \pm 328$ & $156 \pm 130$ & toxic & 0.0002 \\
\hline AMI9 & $10^{-10}$ & 6 & $1101 \pm 263$ & $2727 \pm 313$ & $2581 \pm 277$ & $9.1 \pm 3.6$ & 0.83 \\
& $10^{-9}$ & 6 & $991 \pm 347$ & $2277 \pm 452$ & $1653 \pm 456$ & $47.1 \pm 13.5$ & 0.029 \\
& $10^{-8}$ & 6 & $1139 \pm 322$ & $2742 \pm 237$ & $1371 \pm 346$ & $85.2 \pm 9.2$ & 0.002 \\
& $10^{-7}$ & 4 & $1304 \pm 168$ & $3107 \pm 118$ & $1412 \pm 214$ & $93.8 \pm 5.2$ & 0.003 \\
& $10^{-6}$ & 7 & $1275 \pm 195$ & $2758 \pm 679$ & $1013 \pm 243$ & $116.1 \pm 10.3$ & 0.0001 \\
& $10^{-5}$ & 6 & $889 \pm 113$ & $2051 \pm 644$ & $805 \pm 145$ & $109.2 \pm 5.4$ & 0.0006 \\
\hline \multirow{2}{*}{ AMI9S } & $10^{-10}$ & 5 & $1686 \pm 255$ & $3410 \pm 431$ & $3390 \pm 498$ & $0.8 \pm 8.1$ & 0.96 \\
& $10^{-9}$ & 5 & $1137 \pm 132$ & $2198 \pm 557$ & $1840 \pm 514$ & $38.7 \pm 14.0$ & 0.060 \\
& $10^{-8}$ & 5 & $1033 \pm 216$ & $2050 \pm 368$ & $1507 \pm 352$ & $55.6 \pm 13.6$ & 0.015 \\
& $10^{-7}$ & 5 & $857 \pm 215$ & $2152 \pm 520$ & $1041 \pm 212$ & $85.6 \pm 4.1$ & 0.004 \\
& $10^{-6}$ & 5 & $1139 \pm 291$ & $2194 \pm 700$ & $1180 \pm 247$ & $95.5 \pm 5.3$ & 0.004 \\
& $10^{-5}$ & 4 & $864 \pm 122$ & $1894 \pm 388$ & $785 \pm 144$ & $108.5 \pm 9.1$ & 0.003 \\
\hline
\end{tabular}

TABLE 3. Dose-dependent inhibitory effects of propranolol, AMI9 and AMI9S on the dP/dt max of isolated rat hearts stimulated by $10 \mathrm{nM}$ isoproterenol; $\mathrm{dP} / \mathrm{dt}$ max values $(\mathrm{mmHg} / \mathrm{sec})$ expressed as mean $\pm \mathrm{SD} ; P$ value refers to the comparison between control perfusion (isoproterenol continuously) and continuous co-perfusions of isoproterenol + tested compound. 


\begin{tabular}{|c|c|c|c|c|c|c|c|c|}
\hline $\begin{array}{l}\text { Time post- } \\
\text { injection (min) }\end{array}$ & Heart & Lung & Liver & Kidney & Brain & Muscle & Blood & Fat \\
\hline 0.5 & $4.7 \pm 2.3$ & $14.7 \pm 12.1$ & $3.3 \pm 2.7$ & $8.9 \pm 7.2$ & $0.2 \pm 0.1$ & $0.6 \pm 0.5$ & $3.1 \pm 0.1$ & $0.2 \pm 0.1$ \\
\hline 1 & $4.7 \pm 2.3$ & $13.9 \pm 9.5$ & $3.6 \pm 2.5$ & $12.5 \pm 8.8$ & $0.2 \pm 0.1$ & $0.7 \pm 0.4$ & $1.3 \pm 0.5$ & $0.2 \pm 0.1$ \\
\hline 2 & $5.3 \pm 0.5$ & $13.7 \pm 2.1$ & $5.2 \pm 0.1$ & $12.0 \pm 1.6$ & $0.1 \pm 0.0$ & $1.2 \pm 0.0$ & $1.3 \pm 0.2$ & $0.3 \pm 0.0$ \\
\hline 5 & $4.2 \pm 0.5$ & $9.8 \pm 0.6$ & $5.9 \pm 1.1$ & $11.0 \pm 3.2$ & $0.1 \pm 0.0$ & $1.2 \pm 0.3$ & $1.3 \pm 0.4$ & $0.3 \pm 0.0$ \\
\hline 10 & $2.6 \pm 0.5$ & $5.6 \pm 1.5$ & $3.9 \pm 0.5$ & $6.5 \pm 2.6$ & $0.1 \pm 0.0^{*}$ & $1.0 \pm 0.2$ & $1.5 \pm 0.5$ & $0.3 \pm 0.0$ \\
\hline 15 & $1.8 \pm 0.1 *$ & $4.7 \pm 0.5$ & $2.8 \pm 0.2$ & $4.7 \pm 1.4$ & $0.1 \pm 0.0 *$ & $1.1 \pm 0.0$ & $1.3 \pm 0.1$ & $0.5 \pm 0.1 *$ \\
\hline 30 & $0.9 \pm 0.2 *$ & $3.2 \pm 0.3$ & $1.8 \pm 0.2$ & $2.2 \pm 0.4$ & $0.1 \pm 0.0^{*}$ & $0.6 \pm 0.0$ & $1.2 \pm 0.2$ & $0.2 \pm 0.0$ \\
\hline 45 & $0.6 \pm 0.1^{*}$ & $3.9 \pm 0.3$ & $1.3 \pm 0.1$ & $1.6 \pm 0.1$ & $0.1 \pm 0.1$ & $0.5 \pm 0.0$ & $1.0 \pm 0.3$ & $0.3 \pm 0.1$ \\
\hline 60 & $0.5 \pm 0.1 *$ & $2.7 \pm 0.3$ & $1.0 \pm 0.1$ & $1.2 \pm 0.1$ & $0.1 \pm 0.0 *$ & $0.4 \pm 0.0$ & $1.2 \pm 0.5$ & $0.1 \pm 0.0$ \\
\hline 90 & $0.5 \pm 0.1 *$ & $2.3 \pm 0.5$ & $0.8 \pm 0.1$ & $1.0 \pm 0.2$ & $0.3 \pm 0.2$ & $0.3 \pm 0.1$ & $1.3 \pm 0.2$ & $0.1 \pm 0.0$ \\
\hline 120 & $0.5 \pm 0.1 *$ & $2.0 \pm 0.3$ & $0.7 \pm 0.2$ & $1.3 \pm 0.5$ & $0.1 \pm 0.0$ & $0.3 \pm 0.1$ & $1.1 \pm 0.1$ & $0.1 \pm 0.0$ \\
\hline
\end{tabular}

TABLE 4. Organ biodistribution of $\left[{ }^{125} \Pi\right]$-AMI9 in mice. Values expressed as mean \pm SD of DUR. $* P<0.05$ vs. 1 min. 


\begin{tabular}{|c|c|c|c|c|c|c|c|c|}
\hline $\begin{array}{c}\text { Time post- } \\
\text { injection ( } \mathrm{min})\end{array}$ & Heart & Lung & Liver & Kidney & Brain & Muscle & Blood & Fat \\
\hline 0.5 & $2.5 \pm 0.2$ & $14.3 \pm 0.6$ & $0.5 \pm 0.1$ & $2.7 \pm 0.8$ & $0.2 \pm 0.1$ & $0.9 \pm 0.1$ & $2.2 \pm 0.2$ & $0.1 \pm 0.1$ \\
\hline 1 & $2.5 \pm 0.2$ & $12.9 \pm 1.2$ & $0.6 \pm 0.0$ & $3.0 \pm 1.3$ & $0.1 \pm 0.0$ & $0.7 \pm 0.1$ & $1.7 \pm 0.1$ & $0.2 \pm 0.0$ \\
\hline 2 & $2.4 \pm 0.2$ & $17.1 \pm 1.1^{*}$ & $0.7 \pm 0.1 *$ & $1.6 \pm 0.3$ & $0.1 \pm 0.0$ & $0.5 \pm 0.2$ & $1.9 \pm 0.4$ & $0.4 \pm 0.5$ \\
\hline 5 & $2.3 \pm 0.4$ & $12.3 \pm 4.3$ & $0.7 \pm 0.2$ & $1.0 \pm 0.2 *$ & $0.1 \pm 0.0$ & $0.5 \pm 0.1 *$ & $1.9 \pm 0.2$ & $0.1 \pm 0.0$ \\
\hline 10 & $1.9 \pm 0.4 *$ & $11.1 \pm 0.7$ & $0.6 \pm 0.1$ & $1.1 \pm 0.2$ & $0.2 \pm 0.0$ & $0.7 \pm 0.1$ & $1.8 \pm 0.1$ & $0.3 \pm 0.3$ \\
\hline 15 & $2.1 \pm 0.4$ & $9.8 \pm 2.5$ & $0.7 \pm 0.1$ & $0.8 \pm 0.1 *$ & $0.1 \pm 0.0$ & $0.8 \pm 0.1$ & $2.0 \pm 0.0 *$ & $0.2 \pm 0.0$ \\
\hline 30 & $1.5 \pm 0.1 *$ & $9.9 \pm 0.4 *$ & $0.4 \pm 0.7$ & $0.7 \pm 0.1 *$ & $0.1 \pm 0.1$ & $0.5 \pm 0.1 *$ & $1.2 \pm 0.2 *$ & $0.2 \pm 0.1$ \\
\hline 45 & $1.3 \pm 0.3 *$ & $8.3 \pm 2.1 *$ & $0.4 \pm 0.1$ & $0.5 \pm 0.2 *$ & $0.1 \pm 0.0 *$ & $0.5 \pm 0.3$ & $0.8 \pm 0.1 *$ & $0.2 \pm 0.2$ \\
\hline 60 & $1.3 \pm 0.3 *$ & $9.9 \pm 1.4^{*}$ & $0.4 \pm 0.1 *$ & $0.6 \pm 0.1 *$ & $0.1 \pm 0.0 *$ & $0.5 \pm 0.0 *$ & $0.9 \pm 0.1 *$ & $0.6 \pm 0.6$ \\
\hline 90 & $1.1 \pm 0.2 *$ & $10.7 \pm 0.8^{*}$ & $0.4 \pm 0.0 *$ & $0.5 \pm 0.1 *$ & $0.0 \pm 0.0 *$ & $0.4 \pm 0.1 *$ & $0.7 \pm 0.1 *$ & $0.1 \pm 0.1 *$ \\
\hline 120 & $0.9 \pm 0.2 *$ & $7.9 \pm 1.4^{*}$ & $0.3 \pm 0.0 *$ & $0.4 \pm 0.1^{*}$ & $0.0 \pm 0.0 *$ & $0.5 \pm 0.1 *$ & $0.6 \pm 0.1 *$ & $0.1 \pm 0.1$ \\
\hline
\end{tabular}

TABLE 5. Biodistribution pattern of $\left[{ }^{3} \mathrm{H}\right]$-CGP-12177 in mice. Values expressed as mean \pm SD of DUR. * $P<0.05$ vs. 1 min. 


\begin{tabular}{|c|c|c|c|c|c|c|c|c|}
\hline $\begin{array}{c}\text { Time post- } \\
\text { injection (min) }\end{array}$ & Heart & Lung & Liver & Kidney & Brain & Muscle & Blood & Fat \\
\hline 0.5 & $4.7 \pm 1.5$ & $23.4 \pm 3.5$ & $3.4 \pm 0.3$ & $10.1 \pm 1.3$ & $0.1 \pm 0.0$ & $0.7 \pm 0.0$ & $2.6 \pm 0.4$ & $0.1 \pm 0.0$ \\
\hline 1 & $4.9 \pm 0.7$ & $24.8 \pm 13.6$ & $2.9 \pm 0.2$ & $8.6 \pm 0.7$ & $0.1 \pm 0.0$ & $0.8 \pm 0.3$ & $1.8 \pm 0.3$ & $0.2 \pm 0.1$ \\
\hline 2 & $4.1 \pm 0.4$ & $23.4 \pm 7.0$ & $3.1 \pm 0.6$ & $6.9 \pm 1.2$ & $0.1 \pm 0.0$ & $0.6 \pm 0.1$ & $2.4 \pm 0.4$ & $0.3 \pm 0.3$ \\
\hline 5 & $3.3 \pm 0.8 *$ & $27.7 \pm 4.8$ & $2.7 \pm 0.1$ & $8.8 \pm 0.4$ & $0.1 \pm 0.0$ & $0.5 \pm 0.2$ & $2.2 \pm 0.6$ & $0.3 \pm 0.3$ \\
\hline 10 & $2.4 \pm 0.4 *$ & $35.2 \pm 6.8$ & $1.7 \pm 0.1 *$ & $5.1 \pm 0.3 *$ & $0.1 \pm 0.0$ & $0.5 \pm 0.1$ & $2.4 \pm 0.1 *$ & $0.6 \pm 0.1 *$ \\
\hline 15 & $2.2 \pm 0.8^{*}$ & $24.6 \pm 0.0$ & $2.0 \pm 0.6$ & $6.0 \pm 0.8^{*}$ & $0.1 \pm 0.0$ & $0.5 \pm 0.1$ & $1.9 \pm 0.6$ & $0.2 \pm 0.0$ \\
\hline 30 & $2.1 \pm 0.2 *$ & $26.9 \pm 5.6$ & $1.5 \pm 0.1 *$ & $5.0 \pm 0.8 *$ & $0.1 \pm 0.0$ & $0.6 \pm 0.1$ & $2.3 \pm 0.1^{*}$ & $0.3 \pm 0.1$ \\
\hline 45 & $1.8 \pm 0.2 *$ & $34.8 \pm 8.3$ & $1.1 \pm 0.1 *$ & $4.5 \pm 0.5^{*}$ & $0.1 \pm 0.0$ & $0.5 \pm 0.1$ & $2.7 \pm 0.7$ & $0.3 \pm 0.1$ \\
\hline 60 & $2.2 \pm 0.5^{*}$ & $32.5 \pm 8.5$ & $1.0 \pm 0.1^{*}$ & $2.2 \pm 0.2 *$ & $0.1 \pm 0.0$ & $0.6 \pm 0.2$ & $1.7 \pm 0.5$ & $0.1 \pm 0.0$ \\
\hline 90 & $2.2 \pm 0.3 *$ & $34.3 \pm 7.3$ & $1.1 \pm 0.2 *$ & $2.5 \pm 0.5 *$ & $0.1 \pm 0.0$ & $0.5 \pm 0.1$ & $1.8 \pm 0.5$ & $0.4 \pm 0.3$ \\
\hline 120 & $2.1 \pm 0.2 *$ & $18.2 \pm 1.8$ & $1.1 \pm 0.2 *$ & $1.9 \pm 0.1 *$ & $0.1 \pm 0.0$ & $0.7 \pm 0.1$ & $1.9 \pm 0.1$ & $0.1 \pm 0.1$ \\
\hline
\end{tabular}

TABLE 6. Biodistribution pattern of $\left[{ }^{125} \mathrm{I}\right]$-ICYP in mice. Values expressed as mean \pm SD of DUR. $* P<0.05$ vs. 1 min. 


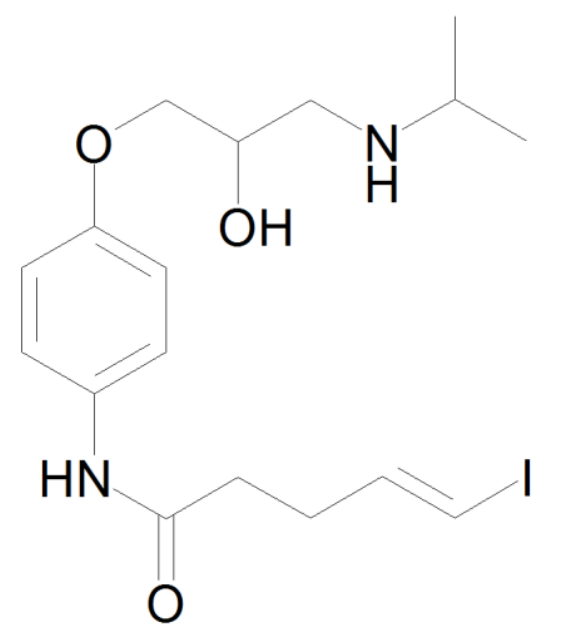




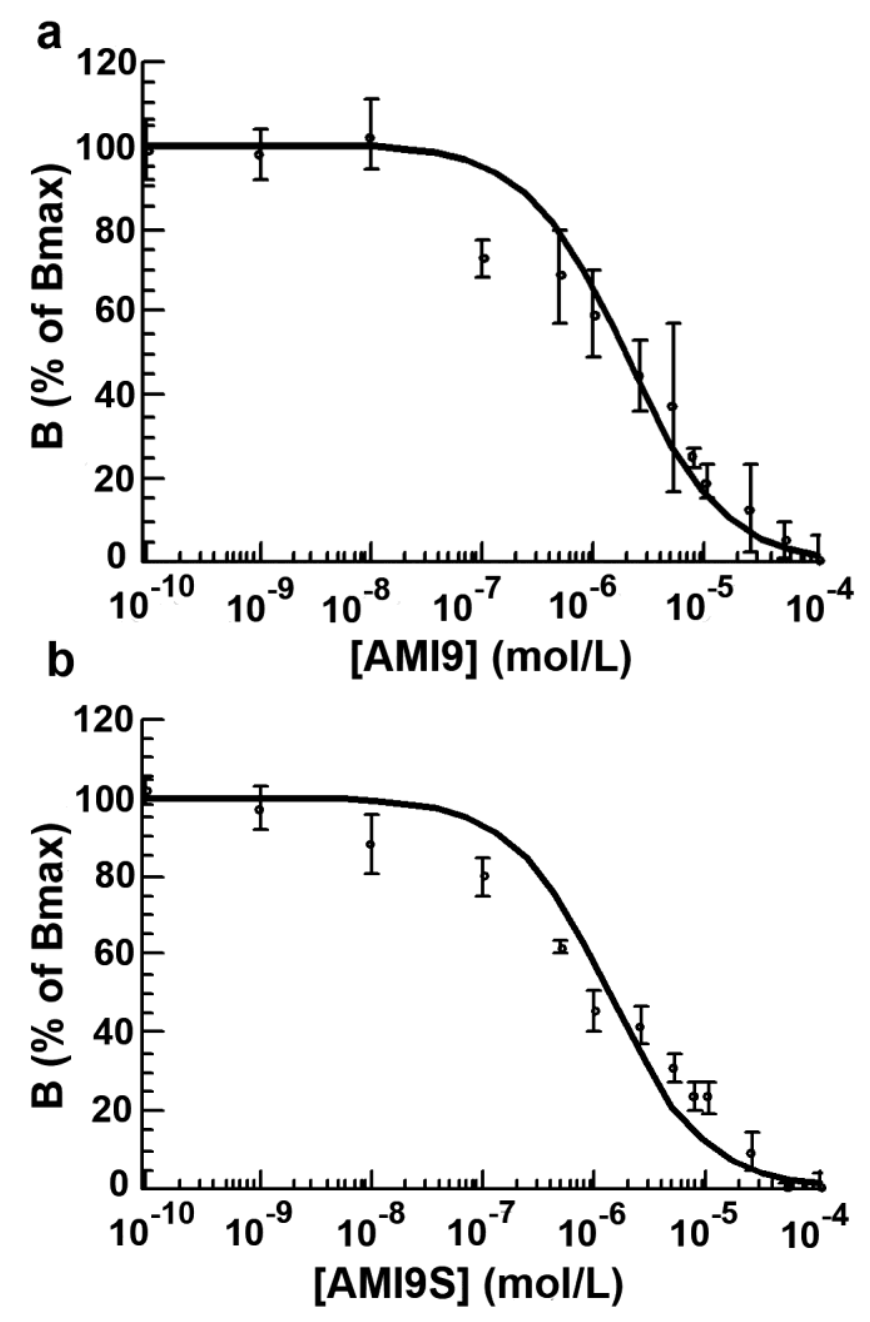




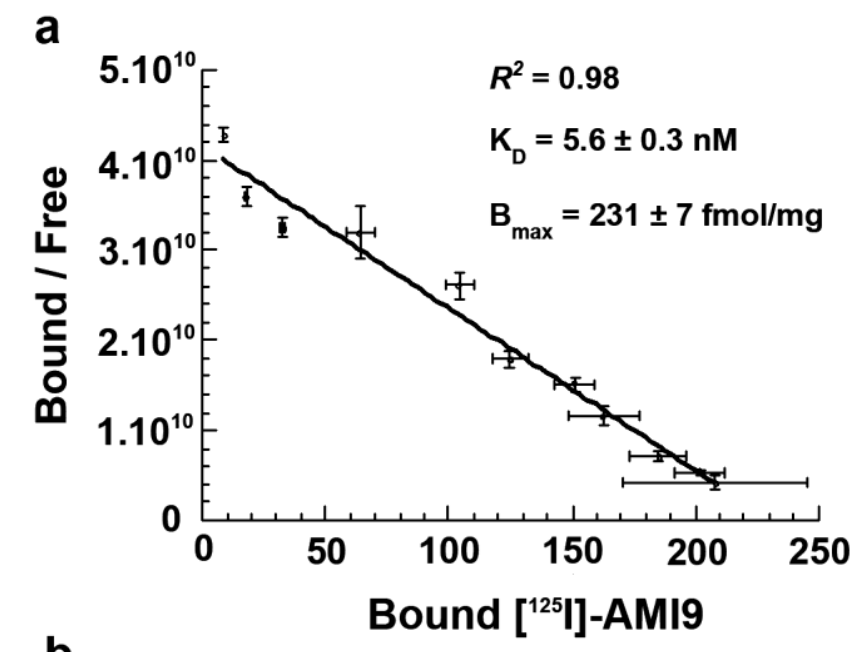

b

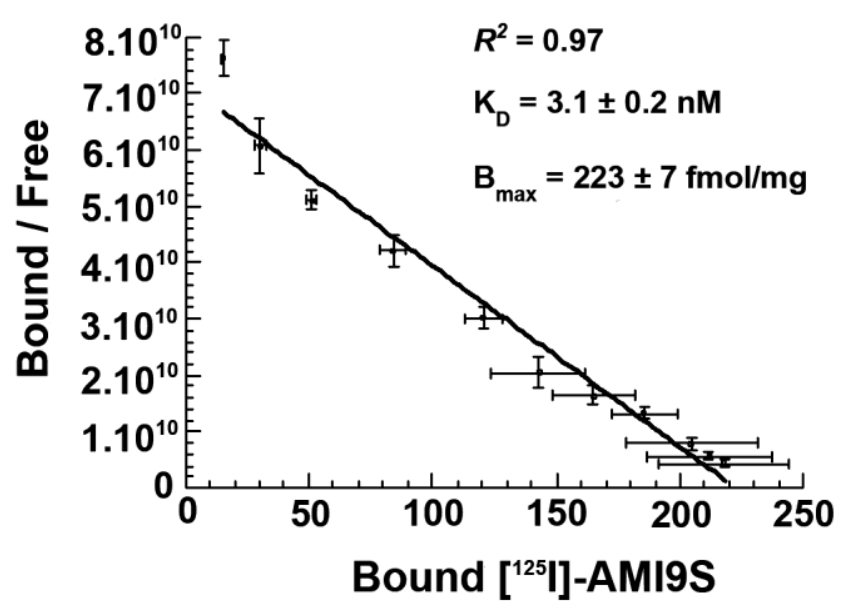

